\title{
4
}

\section{THE UNRAVELLING OF TECHNOCRATIC ORTHODOXY?}

\section{Contemporary knowledge politics in technology regulation}

\author{
Patrick van Zwanenberg
}

\section{Introduction}

Technology regulation has long been an area of governance where the problematic nature of officially sanctioned knowledge regularly spills over into wider political and public settings. From clashes over atmospheric nuclear testing in the 1950 s to more recent disputes over the commercialisation of agricultural genetic engineering, virtually all technology-related controversies of the last 70 years have pivoted around conflicts over the knowledge claims that regulatory institutions invoke to inform and justify policy decisions. Critics have long argued that officially sanctioned knowledge claims reflect a particular, usually very narrow, framing of what are generally profoundly ambiguous issues (Wynne 1975), and frequently provide a false precision in regard to what are often arbitrary and highly uncertain judgements and assessments (National Research Council 1983). They have also stressed that the precise ways in which these forms of knowledge 'closure' occur are invariably shaped by the political commitments and policy preferences of incumbent state and industrial actors, whether intentionally or inadvertently (Jasanoff and Wynne 1998). Any form of closure will, in turn, delimit the kinds of policy and technological options that decision-makers even contemplate, and prefigure the choices made about those options that are subject to consideration (Felt et al. 2007). As a consequence, regulatory decisions are often strongly influenced, even determined, by the political values and policy preferences of states and regulated industries, but those values and preferences are disguised in apparently logical and rational language (Stirling 2008a; Mayer and Stirling 2004; Jasanoff and Wynne 1998).

The evident tensions have been exacerbated by a long-standing historical tendency on the part of scientific and policy institutions everywhere to insist that there are, in fact, no political or normative dimensions to the knowledge claims that inform and justify policy decisions. This has been achieved firstly by depicting 
technology regulation as concerned only with addressing the safety of individual technologies, as if this were logically the only legitimate grounds for social concern about technology, and secondly by treating issues of safety as if they were fully comprehendible and predictable ex ante as a problem of calculable risk, or at least as a resolvable technical uncertainty.

In this portrayal, technological change is assumed to reflect the inevitable unfolding of scientific progress, rather than human choice, while the business of understanding potential harm is a rational scientific problem that can be solved in an impartial and objective way. Technology policy therefore becomes a technocratic exercise of calculating risks to human and environmental health and diminishing them to a socially acceptable level, in order to 'optimise' singular, apparently inevitable pathways of technological change.

It is not difficult to see why this depiction is expedient, at least for some actors, but it is wishful thinking. The world has experienced a long series of major unexpected problems with technologies, from the huge human toll from the use of asbestos, to the effects of chlorofluorocarbons on ozone depletion, to major industrial accidents such as at Chernobyl and Fukushima. These have shown how very serious harm often comes as a complete surprise, or despite very low official estimations of the chances of it occurring or at a magnitude far greater than predicted (Pfotenhauer et al. 2012; Harremoës et al. 2001). Furthermore, the utter failures, at least in some jurisdictions, to secure legitimacy for politically contentious technologies such as civil nuclear power and agricultural genetic engineering have torpedoed the implicit assumption that safety is the only meaningful public issue at stake in relation to the ways in which our technological futures unfold (Wynne 1983).

Policy institutions and jurisdictions have responded very slowly and unevenly, if at all, to these kinds of problems, and to an important critique of orthodox regulation, led by both the environmental and public health movements and by natural and social scientists (e.g. Stirling 2008b; Global Environmental Change Programme 1999; Santillo et al. 1998; Wynne 1982). Even where events and acute crises have made it overwhelmingly clear that at least some aspects of claims to science-based objectivity in regulatory decision-making are highly normative, the traditional depiction of regulation as a singularly rational technocratic endeavour has proved remarkably resilient in many institutions.

In this chapter I reflect on this conundrum through a brief discussion of two areas of contemporary European technology regulation, which I suggest have wider resonance: the cultivation of transgenic plant varieties and efforts to reform pesticide regulation. Both cases illustrate how unfolding events, campaigning and contextual issues and processes can sometimes force a partial 'opening up' of otherwise routine or opaque processes of knowledge closure, potentially heralding a broadening of technology regulation, for example so that policy addresses a wider set of potential vulnerabilities, or compares the pros and cons of different technological practices. Yet both cases also show how a more intellectually honest appreciation of, and response to, the uncertain, contested and provisional nature of much regulatory knowledge is politically very challenging for many institutions and the 
industries they regulate, and how many regulatory agencies and industry bodies have responded, and are responding, to such 'opening up' dynamics by trying aggressively to reassert an orthodox technocratic depiction of regulation, and in doing so shut down the rationale for more ambitious regulatory experimentation.

The more general phenomenon here is that political contexts and processes mediate a dynamic, perhaps dialectic, tension in much contemporary technology regulation - between the long-standing tradition of framing technology regulation around a control-based vision of risk management, supported by governmentindustry knowledge claims, and countervailing pressures to challenge the power embodied in such reductionist framings and to broaden out questions about technological vulnerability, and ultimately technological choice, for wider deliberation and collective decision-making. How such tensions play out in any specific area of regulation and whether a more emancipatory knowledge politics - and in turn transformative technology policy - can be fostered remain open questions. I argue that the emerging sustainability transformation agenda holds considerable potential to help foster such a shift, given that it invites a framing of the ways we think about technological vulnerabilities, and about socio-technical futures, that is fundamentally incompatible with orthodox regulatory approaches.

\section{Transgenic crop regulation and the intractability of 'incertitude'}

More than two decades of protracted conflict and regulatory paralysis in Europe in regard to the cultivation of genetically engineered (GE) crops illustrate very well how different dimensions of what Stirling (2008b) calls 'incertitude' - an unpacking of the broad, colloquial notion of 'uncertainty' (see Box 4.1) - affect and sometimes complicate knowledge production and regulatory decision-making.

In the early 1990s, the brand new European transgenic crop regulatory regime was typical of most areas of technology regulation: its remit was to anticipate and avoid 'adverse effects' on human health and the environment from individual technological artefacts, in this case transgenic crop varieties. The need for, and the potential benefits of, the new technology did not form part of the assessment, but were effectively assumed. Assessment focused, at least initially, on anticipating relatively direct forms of (practically measurable or estimable proxies for) potential harm, which were then evaluated against the benchmark of damage already caused by prevailing technological practice, in this case intensive agriculture. Scientific and regulatory conclusions about the potential 'risks' posed by the new crop technology were reported as if they were derived from an objective assessment of the scientific facts, with little if any acknowledgement of uncertainties, subjective assumptions or limits to what scientists could practically anticipate. This way of analytically defining, conducting and representing technology regulation was not inevitable, but rather followed the practice that had been established almost everywhere in the post-war period (Stirling 2010; Millstone and van Zwanenberg 2002). 


\section{BOX 4.1 DIFFERENT DIMENSIONS OF INCERTITUDE}

Risk - possible outcomes and their likelihoods can be reliably estimated Uncertainty - possible outcomes are clear, but there is no basis for assigning probabilities

Ignorance - neither outcomes nor their probabilities can be fully characterised

Ambiguity - probabilities can in principle be characterised, but there is no agreement over how to define the possible outcomes - for example, in terms of what the problem is, how the object of regulatory attention is bounded and which questions to address

Source: Stirling (2008b)

Right from the outset the new European regime ran into difficulties. The European single market meant that regulations had to be consistent across member states, so the new regime was based on the expectation that authorisation of a new transgenic crop in one member state would apply across Europe. In practice, unanimity proved impossible to obtain.

In the early 1990s, several biotechnology firms applied to release novel GE varieties. Regulators in the countries where the applications had been made accepted the firms' claims, based on field trial data, that adverse effects were unlikely. However, several other countries immediately dissented, claiming that a broader range of plausible potential adverse effects should have been taken into consideration. For example, Denmark and Austria objected to the approval in the UK of herbicidetolerant canola (also known as oil seed rape) on the grounds that commercial cultivation of that variety might result in an increase in overall herbicide usage and, via hybridisation with wild relatives, might create herbicide-tolerant weeds, requiring additional herbicides to be used. These effects had been acknowledged as possible during the initial approval process in the UK but had been discounted, not on the grounds that they were unlikely but because any increase in herbicide usage would be a result of crop management practices, and not a direct harmful effect of the transgenic variety itself, and because the emergence of herbicide-tolerant weeds would be an 'agricultural problem' rather than a cause of 'environmental harm' (Levidow 2001). This was not a disagreement about how evidence should be interpreted but rather reflected ambiguities regarding how 'harm' should be defined and what precisely the potential 'problem' was that regulation ought to be addressing, and therefore what issues should properly fall within the boundary of any assessment. The reasons why the objectors dissented had to do with their own particular agricultural priorities and contexts. Denmark, for example, was trying to reduce agrochemical contamination of groundwater, which it relied on for drinking water.

The European Commission overruled these kinds of objections and approved the new transgenic varieties. Yet the refusal to recognise the validity of these objections, and subsequently many others about the scope and analytical framing of 
assessment, eventually provoked several countries unilaterally to ban crop varieties that had already secured Europe-wide approval. As the decade wore on and GE crops and food became increasingly contentious, a range of broader concerns about the 'problem' posed by transgenic crops began to find expression in public debates. For example, the Italian parliament emphasised the risks of dependence on multinational firms and the threat to traditional crop varieties (Levidow 2009). But these were not issues that regulators were permitted to consider.

The more familiar issue of technical uncertainty was also utterly pervasive. Consider, for example, the potential problem described above of the hybridisation of transgenic canola with wild relatives, creating herbicide-tolerant weeds. Although we know that transfer of canola genes to weedy relatives can occur, measurements of pollen flow at 100 metres from transgenic canola have varied across different data sets by nine orders of magnitude (Meyer et al. 2005). Estimates of the frequency of gene transfer will also depend heavily on contingent management practice, and the development of resistant weeds by selection will also depend on herbicide use practices by farmers, which are also highly variable. As Meyer and colleagues put it: 'obvious problematic effects ... can be identified. To what extent they should be regarded as harmful to the environment is a matter of interpretation. Credible probability calculations cannot be made' (Meyer et al. 2005: 237).

In such circumstances, subjective judgements have to be invoked if the conclusions of assessments are not to remain chronically open-ended. For example, what kinds and qualities of evidence are sufficient to conclude that herbicide-tolerant weeds will emerge as, say, a serious environmental problem? Regulatory institutions' responses to such uncertainties were contentious, but not only because the necessarily subjective judgements deployed were invariably represented as flowing from the scientific 'facts'.

In addition, several critics argued that such judgements were deployed inconsistently, with evidence suggestive of harm assumed to be 'insufficient' far more readily than evidence indicative of the absence of harm (Hilbeck et al. 2012; Levidow 2001). In the late 1990s, for instance, a laboratory study on the ecological effects of transgenic insecticidal maize reported significant mortality among lacewing butterfly larvae (a beneficial predator insect often found in maize fields) that had been fed on another species of caterpillar that was first raised on GE maize leaves. UK advisers did not challenge these experimental findings but argued that the laboratory study was not a realistic representation of the field situation - for example, because the larvae would have had a more varied diet in real-world conditions, and would therefore have been exposed to less GE maize (Wynne 2006). Critics pointed out that 'although such hypotheses were not unreasonable' they were almost exclusively made about studies that indicated potential harm: laboratory-based observations that suggested there was no harm from new transgenic plant varieties were routinely taken to be an adequate representation of real field situations (Wynne 2006; Levidow 2001).

Ignorance about the consequences of cultivating GE crops was an even more formidable problem, but it was barely recognised as such, and its implications were neglected. By definition, ignorance cannot be identified except after the fact, but it 
is interesting to observe how scientists and regulators sometimes diminished earlier states of 'institutional ignorance', in the sense that categories of adverse effect or causal pathways of harm that were not initially recognised by regulators (and so were not made the subject of questioning) were later discovered. The above example of the lacewing butterfly larvae study illustrates this point. Early regulatory-scientific studies of the possible effects of insecticidal GE maize on 'non-target harm' were based on investigating the direct effects of the insecticidal toxin expressed in GE maize varieties on beneficial insects (Levidow 2003). Those tests had found no additional harm from the GE maize. However, experimental tests were later performed by a university on carnivorous insects (i.e., the lacewing larvae study) further along the food chain in what is called a tri-trophic test (i.e., involving the plant, a pest and a predator). This more indirect causal pathway did indicate harm, in ways that had not been previously recognised or considered.

This example of institutional ignorance is entirely normal. Anticipatory regulatory knowledge about the consequences of commercially growing GE plants, based on small numbers of field trials and laboratory studies, has no chance of adequately capturing the complexity, contingency and variety of the conditions of actual commercial use. In part this is because of a host of practical constraints on what can be practically explored, but it is also because of normal scientific and regulatory commitments to particular kinds of theoretical models, testing methods and assumptions (Wynne 1992). Such commitments are sometimes questioned and enlarged, as part of a normal healthy process of scientific learning, as in the above example - although it is telling that in that case the prevailing experimental design was only re-examined by a non-regulatory-scientific institution in a context of intense public concern about the new crop technology.

\section{A window of opportunity?}

Intra-European disputes over the licensing of GE crops, particularly in relation to competing understandings as to what precisely the potential 'problem' was with the new crop technology, and therefore what kinds of questions ought to be explored, but also over what should count as adequate or sufficient evidence of safety, posed a serious challenge to the prospects of arriving at common regulatory decisions. One response would have been to recognise the challenges of incertitude, which were increasingly obvious, and which social scientists, NGOs and some protagonists had helped highlight. Taking those challenges seriously would have entailed making explicit and justifying - and if necessary renegotiating - the inevitable normative assumptions that are part and parcel of regulatory-scientific assessment. This would have entailed, for example, debating what burdens of proof were appropriate in particular situations of technical uncertainty, or what the relevant scientific questions to ask should be, given ambiguity over the potential problems posed by GE crop technology. Taking ignorance seriously might have involved adopting a less hubristic representation of what anticipatory assessment can achieve, and might have involved trying to nurture a learning culture within regulatory institutions. 
Initially, it appeared that something approaching these kinds of responses might be forthcoming. By the late 1990s, concerns about the safety and acceptability of GE crops had exploded as a public issue across Europe. Environment ministers from several member states refused to support any more applications for new crop varieties until substantial revisions to the legislation were made. Ministers demanded that a wider range of potential risks be considered in applications - in particular, indirect effects that arise from the changed agricultural practices associated with a GE crop. They also wanted an obligation to monitor crops after approval, the rationale being to check for any adverse consequences that had not been discovered in experimental field trials, and for food and animal feed produced using GE plants to be traceable throughout the product chain, in order to ensure that food could be withdrawn if new evidence emerged regarding unknown health hazards (Levidow et al. 2005). Interestingly, these latter proposed revisions showed a recognition of ignorance about the potential consequences of agricultural biotechnology commercialisation, and an institutional attempt to try to diminish our vulnerability to such 'unknown-unknowns' (Wynne 1992).

New legislation incorporating all of these demands came into force in 2001. This occurred in the wake of the BSE or 'mad cow' crisis of 1996, shortly after which it became clear that profound uncertainty about whether the cattle disease might be transmitted to humans had been entirely glossed over by ministers and officials, in both the UK and within the European Commission. In the wake of the BSE crisis many regulatory institutions began to emphasise how important it was from now on that the institutions responsible for the assessment of scientific evidence should be 'independent' and that scientists should ensure that levels of uncertainty should be explicitly identified and communicated in plain language to decision-makers, and that any assumptions should be explicitly documented (OST 2005). A key driver of these reforms was the actions of government chief scientists, who had been alarmed not only by the potential catastrophe of BSE but also by the way in which 'science' had been used as political cover for ministers and officials throughout the saga (van Zwanenberg and Millstone 2005).

\section{Reasserting orthodoxy at the European Commission}

In practice, however, a more intellectually honest treatment of incertitude was not forthcoming. Instead, the Commission and its advisers attempted to reassert a modified version of the orthodox, technocratic depiction of regulation, although in a partial concession - regulation was now split into two distinctive parts: 'risk assessment', which was represented as a policy-free, objective scientific endeavour, and 'risk management', which involved some normative decisions (Millstone 2009). Levidow (2017) notes how many senior people at the Commission had diagnosed the conflicts over GE crop assessment and decision-making over the previous decade as arising from national politics interfering with the proper scientific basis of risk regulation. New legislation introduced a centralised procedure of authorisation by the European Commission (Dolezel et al. 2011), and the idea was that the new 
European Food Safety Agency (EFSA) would now play a more central role in scientific assessment of GE crops, while risk management would be the responsibility of the European Commission. As Directorate-General for Health and Consumers Commissioner David Byrne put it in 2002:

[EFSA's] independence will ensure that scientific risk assessment work is not swayed by policy or other external considerations.... [The development of EFSA's reputation for independence and excellence] will put an end to competition in such matters among national authorities in the Member States. We have seen evidence of this in the past and I hope that it will over time become a thing of the past (Byrne 2002: 3-4).

However, the new role for EFSA only exacerbated intra-European disputes. After several new transgenic crop varieties were approved by the Commission in the 2000s, Germany, France, Austria and Italy declared national prohibitions on their cultivation, which they were permitted to do under a 'safeguard clause' if new scientific information demonstrated a risk to human health or the environment. EFSA concluded that all the prohibitions lacked sufficient scientific evidentiary support and the Commission ruled that the bans were illegal - although none of the member states concerned backed down.

The unilateral bans had been made for the same kinds of reasons that had underpinned disputes in the previous decade: disagreements over which effects should count as 'adverse', and over what should count as meaningful or adequate or relevant evidence for a risk assessment (Levidow 2017; Wickson and Wynne 2012). EFSA's role was thus critical in facilitating the continuing impasse. For the Agency there was only one relevant framing of the scientific-regulatory problem and only one plausible interpretation of the evidence, namely its own. Its own scientific guidelines required Agency staff to make all assumptions explicit (EFSA 2009), but in practice it had ignored normative judgements within science, or represented them as scientific considerations (Levidow 2017).

For some analysts, the Commission and EFSA's 'normative-free' sound science representation of transgenic crop assessment reflects an entrenched institutional commitment to the European single market, which in turn requires a single regulatory system and therefore a centralised, standardised risk assessment (Wynne 2006). For others it is more an attempt by the Commission and EFSA to disguise a probiotech agenda - the Commission sees biotech as essential for future growth and competitiveness - under the guise of unitary science (Levidow 2015; Dolezel et al. 2011). Yet others point to naive beliefs in the political neutrality and universality of regulatory science on the part of some scientists and officials, and in particular in the scientistic assumption that science ought to define the human meaning of issues such as GE crop innovation. In this reading, any concerns other than those identified by officially sanctioned scientific institutions must be illegitimate 'hidden interests' and 'anti-scientific', especially if they are not exclusively about public or environment health but extend to cover public concerns about the politicaleconomic effects, or drivers, of GE crop innovation (Wynne 2014). 
Additional explanations are not necessarily incompatible with any of the above. For example, Commission officials may have concluded that it was too politically risky to acknowledge openly the contingent and highly uncertain nature of regulatoryscientific knowledge because it could then become very difficult to draw a line and prevent further, endless deconstruction of whatever claims were officially sanctioned. The political risk here is not just that institutions are unable to pretend that contentious policy decisions can be justified solely by recourse to evidence, but that events may quickly spiral out of control. An explicit acknowledgement that we cannot predict future impacts might lead logically to demands for expensive or burdensome controls, or to politically problematic questions being posed, such as 'why then are we supporting this technology?', 'what and whose needs is it designed to satisfy?' and 'what are the alternatives?' It is far easier politically, perhaps, to insist that knowledge claims are universal and complete. British officials often made this kind of political calculation during the BSE saga, for instance (van Zwanenberg and Millstone 2005).

\section{Pesticide regulation and the sustainability transformation agenda}

In attempting to impose a singular meaning of 'risk', and a single analytical treatment of it, on multiple European countries with diverse sets of concerns and agricultural priorities, European GE crop regulation has scuppered any prospect of common regulatory decisions. By contrast, in the field of pesticide regulation standard approaches to risk regulation have been stretched to accommodate a much wider analytical framing. A significant factor influencing this is the emerging sustainability transformation agenda, which has challenged some long-held orthodoxies in pesticide regulation.

In 2011, two new pieces of European legislation on pesticide approval and pesticide use came into force (EC 2009a; 2009b). The new legislation contained four novel regulatory measures that drive a coach and horses through the traditional analytical treatment of pesticide regulation. These are to:

- use hazard-based cut-off criteria to prohibit all pesticides that exhibit the intrinsic potential of serious toxicity or persistence;

- use comparative hazard assessment to substitute authorised chemical pesticide uses for the least hazardous alternatives, including non-chemical techniques;

- $\quad$ promote non-chemical pest management, specifically organic farming and

- $\quad$ establish integrated pest management in all agricultural practice (in which biological, agronomic and physical forms of insect, weed and fungal control are given priority over chemical control).

The new measures represent a profound challenge to the central regulatory tenet that anticipatory risk assessment provides a sufficiently reliable and complete basis upon which to anticipate and control potential harm from the commercial use of a technology. Consider, for example, the new hazard-based cut-off criteria measure, 
which means that the intrinsic toxic potential or persistence of a compound becomes grounds for prohibition. The traditional risk-based approach would also involve estimating the likely exposure to the compound under different conditions of use and to different populations; it would model and estimate dose-response relationships based on experimental rodent studies, and then derive estimates of the magnitude of potential harm to humans under different use scenarios, as the basis upon which regulatory decisions are taken. That orthodox approach is, however, afflicted by persistent uncertainties because numerical estimates of the magnitude of harm at different levels of exposure (or more typically the derivation of a threshold level of exposure that constitutes 'no harm') are usually impossible to derive without deploying a series of cumulative, entirely subjective assumptions (Bailar and Bailar 1999). They are also vulnerable to ignorance - for example, because relevant exposure pathways may be entirely unknown (Wynne 1992).

The adoption of a hazard-based approach (long advocated in the literature on precautionary forms of appraisal, see Lofstedt 2011 and Harremoës et al. 2001) does not avoid vulnerability to incertitude. Important forms of toxicity may be unknown and therefore remain untested.Yet it substantially diminishes such vulnerability, for the reasons provided above. It errs on the side of caution, on the grounds that we are unlikely to be able reliably to identify thresholds of safe exposure to compounds that are, for instance, carcinogens or endocrine disruptors, or to ensure that actual use of such compounds will conform to regulatory assumptions about working practice.

The particular formulation of the measure on comparative hazard assessment under these new pieces of European legislation - in which non-chemical techniques of pest control must be included as a comparator - also demolishes another orthodox regulatory tenet: the traditional bounding of the 'object' of regulatory scrutiny as only involving individual technological artefacts. Yet that bounding is ambiguous. There is no scientific reason why, instead, the object of regulatory attention should not extend to multiple artefacts (and their synergies and interactions), or an entire technological system or technological trajectory or, as in the new European legislation, an artefact assessed by comparison with alternative technological or policy means of obtaining the same social goal. Indeed, since the greater scope of specificity of such a comparative approach would be more scientifically rigorous, the real reason for restricting attention in the conventional approach must be recognised instead as expediency, in favour of the privileged interests whose particular innovations receive such singular treatment.

More generally, the combination of the four new measures under the new legislation - which both increase regulatory pressure to withdraw existing chemical technologies and support the creation of non-chemical alternatives - effectively defines the entire system of chemical pesticide-based crop production itself as a source of vulnerability, even though that system is based on approved pesticides. The purpose of regulation is no longer the orthodox one of 'optimising' supposedly selfunfolding pathways of chemical pesticide-based agricultural production, but rather of redirecting those pathways and transforming agricultural production. 
What, then, prompted this much wider analytical framing of pesticide regulation? The novel assessment measures were drafted by Green Party Members of the European Parliament on the European Parliament's Environment, Public Health and Food Safety Committee, and then steered through the legislative process with the support of some of the smaller EU states (Bozzini 2017; Panke 2012). The measures were strongly informed by ideas about precautionary forms of technology appraisal, and specifically long-standing concerns about the failure of orthodox pesticide regulation to anticipate and control threats to human health and the environment (Bozzini 2017: 66). In 2019, the committee emphasised the central role of pesticides in the collapse in insect species, farmland birds and other biodiversity, and argued that current dependence on pesticides was 'incompatible with sustainable agriculture' (European Parliament 2019: 3). It described the new legislation as 'a prerequisite for ... accomplishing a transition towards sustainable agriculture' (ibid.: 11). Here, then, we see a new political context, shaped by the rise of precautionary thinking, and by the emerging 'sustainability transformation' agenda, and which, in response to existential environmental threats, seeks to reframe the traditional regulatory focus, moving from the management of individual technologies to fostering transformative socio-technical change (cf. Intergovernmental Science-Policy Platform on Biodiversity and Ecosystem Services 2019).

\section{A reassertion of orthodoxy?}

Unsurprisingly, the new measures were heavily criticised by many governments and by the chemical pesticide industry, both before and after the legislation came into force. In 2008, for example, the UK's Pesticide Safety Directorate objected to the then proposed hazard-based cut-off criteria, insisting that 'no meaningful benefits to public health protection from any criteria, beyond those delivered by the existing risk assessment arrangements, have been demonstrated' (cited in Bozzini 2017: 71). Those remarks are a defence of the fundamental orthodox regulatory assumption that asserted risk parameters, and their supposed means for definitive quantification, provide an entirely adequate basis for control - an assumption that, of course, the new legislative measures fatally undermine.

Tellingly, the UK government has interpreted the legislative obligation to establish integrated pest management in all agricultural practice as an issue of economic optimisation, rather than as a means of reducing harm, on the basis that risk-based regulatory approval of pesticides already adequately manages safety (Department for Environment, Food and Rural Affairs 2012). It has therefore made minimal efforts to support the adoption of integrated pest management, suggesting instead that this should be a voluntary option for utility-maximising farmers. As with GE crop regulation, explicit recognition of the challenges of incertitude, and the implications this logically entails for broadening the scope and ambition of regulatory decisionmaking, has prompted a reaction on the part of some jurisdictions to reassert an orthodox technocratic depiction of regulation. 
It remains unclear how this will play out. The European Parliament has described how, in the eight years since the new legislation came into force, implementation has become bogged down in arguments about the desirability, precise meaning and practical implications of many of the proposed new objectives (European Parliament 2019; 2018). The introduction of the hazard-based 'cut-off' assessment of substances was delayed to 2014, and five years later had resulted in the prohibition of only one pesticide active ingredient; meanwhile several member states and the agro-chemical industry have been lobbying to drop the use of the hazard-based cut-off assessment altogether. Comparative assessment began in 2015, but so far no compounds have been substituted for safer alternatives. Little progress, in most member states, has been made on encouraging the use of alternative pest control techniques or the adoption of integrated pest management. Instead, there has been an increase in the overall volume of chemical pesticide use across the EU as a whole (ibid.).

\section{Conclusion}

This chapter has argued that the contemporary politics of technology regulation play out through a key tension: between an established narrow framing of what is at stake in technology regulation, namely the optimisation of singular pathways of technological progress based on a control-based vision of risk management, and countervailing pressures to challenge those reductionist framings and open up questions about technological vulnerability, and ultimately technological choice, to wider deliberation and collective decision-making.

The experience of European regulation of transgenic plant varieties shows how a key moment of 'opening up' was associated with processes of regulatory harmonisation, following the creation of the European single market, and the fallout from the BSE crisis. In the case of pesticide regulation, new, emergent political processes associated with ideas about precaution and the 'sustainability transformation' agenda have challenged established approaches to assessment. Both cases illustrate how contestation over knowledge can unsettle established regulatory practice and prompt a broadening of the scope of regulation - radically so in the pesticides case. They also illustrate how some institutions and industry bodies have responded by trying to reassert an orthodox depiction of knowledge and regulation, thus undermining a rationale for more ambitious, potentially transformative, forms of policy.

The pesticides case suggests that the sustainability transformation agenda may be a particularly significant, emerging aspect of the political contexts that mediate the tensions described in this chapter. Propelled onto policy agendas by the twin crises of climate breakdown and biodiversity collapse, the significance of the transformation agenda is that it invites a framing of the ways we think about technological vulnerabilities and of socio-technical futures that is fundamentally incompatible with orthodox regulatory approaches. That agenda focuses policy attention on the vulnerabilities posed by entire trajectories of linked socio-technical change, rather than the threats presented by individual artefacts; on questions about what kinds of futures we want, rather than the assumption that there is a single deterministic pathway of progress and 
on questions about the multiple contending pathways involved in getting there, and so the importance of appreciating plural knowledge and deliberating among different options, rather than denial of ambiguity. Above all, it undermines the orthodox assumption that regulation can adequately anticipate and control the vulnerabilities posed by our unfolding technological futures. If that were so, why is there an urgent need to transform established socio-technical practice?

\section{References}

Bailar, J.C. and Bailar, A.J. (1999) 'Risk Assessment-the Mother of All Uncertainties: Disciplinary Perspectives on Uncertainty in Risk Assessment', Annals of the New York Academy of Sciences 895: 273-285

Bozzini, E. (2017) Pesticide Policy and Politics in the European Union. Regulatory Assessment, Implementation and Enforcement, London: Palgrave Macmillan

Byrne, D. (2002) 'EFSA: Excellence, Integrity and Openness', speech at inaugural meeting of the European Food Safety Agency Management Board, Parma, Italy: EFSA, https:// ec.europa.eu/commission/presscorner/detail/en/SPEECH_02_405

Department for Environment, Food and Rural Affairs (2012) UK National Action Plan for the Sustainable Use of Pesticides (Plant Protection Products), London: UK Department for Environment, Food and Rural Affairs

Dolezel, M., Miklau, M., Hilbeck, A. et al. (2011) 'Scrutinizing the Current Practice of the Environmental Risk Assessment of GM Maize Applications for Cultivation in the EU', Environmental Sciences Europe 23: 33

European Commission (2009a) Regulation (EC) No 1107/2009 of the European Parliament and of the Council of 21 October 2009 Concerning the Placing of Plant Protection Products on the Market and Repealing Council Directives 79/117/EEC and 91/414/ EEC

- (2009b) Directive 2009/128/EC of the European Parliament and of the Council of 21 October 2009 Establishing a Framework for Community Action to Achieve the Sustainable Use of Pesticides

European Food Safety Agency (2009) 'Guidance on Transparency in the Scientific Aspects of Risk Assessment Carried out by EFSA, Part 2: General Principles', EFSA Journal 1051: 1-22

European Parliament (2019) 'Report on the Implementation of Directive 2009/128/EC on the sustainable Use of Pesticides (2017/2284(INI))', A8-0045/2019

- (2018) 'Report on the Union's Authorisation Procedure for Pesticides (2018/ 2153(INI))', A8-0475/2018

Felt, U. et al. (2007) 'Science and Governance: Taking the European Knowledge Society Seriously', Report of the Expert Group on Science and Governance to the Science, Economy and Society Directorate, Directorate-General for Research, European Commission

Global Environmental Change Programme (1999) The Politics of GM food: Risk, Science and Public Trust, Brighton: ESRC Global Environmental Change Programme, Special Briefing No. 5

Harremoës, P., Gee, D., MacGarvin, M., Stirling, A., Keys, J., Vaz, S.G. and Wynne, B. (eds) (2001) Late Lessons from Early Warnings: The Precautionary Principle 1896-2000, Brussels: European Environment Agency: Environmental Issue Report 22

Hilbeck, A., Meier, M. and Trtikova, M. (2012) 'Underlying Reasons of the Controversy over Adverse Effects of Bt Toxins on Lady Beetle and Lacewing Larvae', Environmental Sciences Europe 24: 1-5 
Intergovernmental Science-Policy Platform on Biodiversity and Ecosystem Services (2019) 'Summary for Policymakers of the Global Assessment Report on Biodiversity and Ecosystem Services of the Intergovernmental Science-Policy Platform on Biodiversity and Ecosystem Services', Bonn: IPBES

Jasanoff, S. and Wynne, B. (1998) 'Science and Decision-making', in S. Rayner and E. Malone (eds) Human Choice and Climate Change. Vol 1 The Societal Framework, Washington DC: Batelle Press: 1-87

Levidow, L. (2017) 'Substituting a Fictional "Science” for Public Accountability: Legitimacy Problems of the EU's Regulatory Framework for GM Products', in L.E. San-Epifanio (ed) Towards a New Regulatory Framework for GM Crops in the European Union: Scientific, Ethical, Social and Legal Issues and the Challenges Ahead, Wageningen: Wageningen Academic Publishers

- (2009) 'Making Europe Unsafe for Agbiotech', in P. Atkinson, P. Glasner and M. Lock (eds) The Handbook of Genetics and Society: Mapping the New Genomic Era, Genetics and Society, London: Routledge

_ (2003) 'Precautionary Risk Assessment of Bt Maize: What Uncertainty?', Journal Invertebrate Pathology 83: 113-117

- (2001) 'Precautionary Uncertainty: Regulating GM Crops in Europe', Social Studies of Science 31.6: 842

Levidow, L., Carr, S. and Wield, D. (2005) 'European Regulation of AgriBiotechnology: Precautionary Links between Science, Expertise and Policy', Science and Public Policy 32.4: 261-276

Lofstedt, R. (2011) 'Risk Versus Hazard-How to Regulate in the 21st Century', European Journal of Risk Regulation 2: 149-168

Mayer, S. and Stirling,A. (2004) 'GM Crops: Good or Bad? Those Who Choose the Questions Determine the Answers', EMBO Reports 5.11: 1021-1024

Meyer, G., Folker, A.P., Jørgensen, R.B., Krauss, M.K.V., Sandøe, P. and Tveit, G. (2005) 'The Factualization of Uncertainty: Risk, Politics, and Genetically Modified Crops - A Case of Rape', Agriculture and Human Values 22: 235-242

Millstone, E. (2009) 'Science, Risk and Governance: Radical Rhetorics and the Realities of Reform in Food Safety Governance', Research Policy 38: 624-636

Millstone, E. and van Zwanenberg, P. (2002) 'The Evolution of Food Safety Policy-Making Institutions in the UK, EU and Codex Alimentarius', Social Policy and Administration 36.6: 593-609

National Research Council (1983) Risk Assessment in the Federal Government: Managing the Process, Washington, DC: National Academy Press

Office of Science and Technology (2005) Scientific Analysis in Policy Making, London: Office of Science and Technology

Panke, D. (2012) 'Being Small in a Big Union: Punching Above their Weights? How Small States Prevailed in the Vodka and the Pesticides Cases', Cambridge Review of International Affairs 25.3: 329-344

Pfotenhauer, S.M., Jones, C.F., Saha, K. and Jasanoff, S. (2012) 'Learning from Fukushima', Issues on Science and Technology 28.3: 79-84

Santillo, D., Stringer, R., Johnston, P. and Tickner, J. (1998) 'The Precautionary Principle: Protecting against Failures of Scientific Method and Risk Assessment', Marine Pollution Bulletin 36.12, 939-950

Stirling,A. (2010) 'From Enlightenment to Enablement: Opening up Choices for Innovation', in A.López-Claros (ed) The Innovation for Development Report, London: Palgrave Macmillan (2008a) 'Opening Up and Closing Down: Power, Participation and Pluralism in the Social Appraisal of Technology', Science Technology and Human Values 33.2: 262-294 


\section{Patrick van Zwanenberg}

(2008b) 'Science, Precaution, and the Politics of Technological Risk: Converging Implications in Evolutionary and Social Scientific Perspectives', Annals of The New York Academy Of Sciences 1128: 95-110

van Zwanenberg,P. and Millstone,E. (2005) BSE: Risk, Science and Governance, Oxford: Oxford University Press

Wickson, F. and Wynne, B. (2012) 'Ethics of Science for Policy in the Environmental Governance of Biotechnology: MON810 Maize in Europe', Ethics, Policy and Environment 15.3: $321-340$

Wynne, B. (2014) 'Further Disorientation in the Hall of Mirrors', Public Understanding of Science 23.1: 60-70

- (2006) 'GMO Risk Assessment under Conditions of Biological (and Social) Complexity', in Bundesministerium für Gesundheit und Frauen (BMGF), The Role of Precaution in GMO Policy Berlin/Bonn: BMGF: 30-46

- (1992) 'Uncertainty and Environmental Learning: Reconceiving Science and Policy in the Preventive Paradigm', Global Environmental Change 2: 111-137

- (1983) 'Redefining the Issues of Risk and Public Acceptance: The Social Viability of Technology', Futures 15: 13-32

(1982) Rationality and Ritual: The Windscale Inquiry and Nuclear Decisions in Britain, Chalfont St. Giles: British Society for the History of Science

(1975) 'The Rhetoric of Consensus Politics: A Critical Review of Technology Assessment', Research Policy 4.2: 108-158 